\title{
Diagnóstico Estructural a Través de la Prueba Persona Bajo la Lluvia en Niños y Niñas de 9 a 11 Años de Edad, Víctimas de Agresiones Sexuales Crónicas
}

\section{Structural Diagnosis Using the Person in Rain Test in Children 9 to 11 Years old, Victims of Chronic Sexual Abuse}

\author{
Alejandro Pool \\ Universidad Santo Tomás
}

\begin{abstract}
La presente investigación consistió en establecer el diagnóstico estructural, a la luz de la teoría de las relaciones objetales de Otto Kernberg, en niños y niñas de 9 a 11 años de edad, víctimas de agresiones sexuales crónicas a través de la prueba proyectiva gráfica Persona Bajo la Lluvia. Se efectuó una comparación con un grupo control constituido por niños y niñas de los cuales no se tenía la sospecha de que hubieran sido agredidos sexualmente. Los resultados obtenidos confirmaron la hipótesis propuesta de que los niños y niñas victimizados sexualmente presentarían en mayor medida una organización limítrofe de la personalidad, en relación a los niños de los que no se tenía la sospecha de que hubieran sido vulnerados en sus derechos sexuales.
\end{abstract}

Palabras Clave: Prueba Persona Bajo la Lluvia, diagnóstico estructural, agresiones sexuales infantiles.

This study aimed to determine structural diagnosis in light of Otto Kernberg's object relations theory, in children from 9 to 11 years old, victims of chronic sexual abuse throught the proyective test Person in Rain. These results were compared with a control group conformed by boys and girls who, presumably, were not victims of sexual abuse. The obtained results confirm the proposed hypothesis that sexually victimized children will tend to show a borderline organization compared to the control group.

Keywords: Person in the Rain Test, structural diagnosis, child sexual abuse.

Las agresiones sexuales infantiles ${ }^{1}$ (ASI) ocasionan un daño psíquico profundo en la víctima y su entorno familiar. Tales transgresiones están sujetas a persecución penal al ser constitutivas de delito. La dificultad que representa el aportar evidencia probatoria del daño psíquico asociado a ASI hace necesario el desarrollo de instrumentos que contribuyan a la evaluación de las secuelas de tales vulneraciones.

La prueba Persona Bajo la Lluvia (PBLL) es una prueba proyectiva gráfica que se ha venido empleando en forma creciente como una herramienta que contribuye al diagnóstico clínico-pericial, proceso

\footnotetext{
Alejandro Pool Burgos, Escuela de Psicología, Universidad Santo Tomás.

La correspondencia referente a este artículo deberá dirigirse al autor a: Rosa Lillo 2370, Arica, Chile. E-mail: alejandropoolb@yahoo.com

Aun cuando el término abuso sexual es más común en la literatura para referirse al conjunto de atentados sexuales, se ha preferido emplear la denominación de agresiones sexuales, debido a que en nuestro país, jurídicamente el primero de ellos se refiere al delito expresado en al artículo 366 del Código Penal, y comprende aquellos actos de significación sexual que pueden o no implicar un contacto corporal con la víctima, pero sin penetración peneal. Por otra parte la denominación de agresiones sexuales conserva la amplitud de referirse a cualquier transgresión de los límites corporales en el ámbito de lo sexual.
}

terapéutico reparatorio y pronóstico de niños victimizados sexualmente. El presente trabajo pretende aportar evidencia empírica y teórica respecto de dicho instrumento en relación a la evaluación y comprensión del daño psíquico producido por las agresiones sexuales infantiles crónicas.

\section{Antecedentes}

\section{El Daño Psíquico Producido por las Agresiones Sexuales Infantiles Crónicas y el Trastorno Limitrofe de la Personalidad en la Infancia}

Las consecuencias de las agresiones sexuales sobre el psiquismo del menor dependen del entrecruzamiento de distintas variables. Dentro de éstas se encuentran: el tipo de vínculo con el agresor, tipo de delito, presencia de amenazas y soborno, miedo al castigo, conflicto marital, separación de los padres biológicos, psicopatología de algún miembro familiar, consumo parental de sustancias, abuso físico, psicopatología del niño/a, percepción de daño, sentimientos de culpabilidad del niño/a, autorreferencia de las figuras significativas, cronicidad, frecuencia, tiempo de acercamiento, reacción ante la develación, sostén familiar y social, recursos personales y resi- 
liencia (Barudi, 1998; Castiglioni, Escaff \& Salinas, 2004; Centro de Asistencia a Víctimas de Atentados Sexuales [CAVAS], 2004; Huerta, Maric \& Navarro, 2002; Intebi, 1998; Johnson, 2004; Miotto, 2001; Molnar, Buka \& Kessler, 2001).

El hecho de que la presente investigación indague sobre el daño psíquico producido por las ASI crónicas se debe a que éstas tienden a predominar en los casos en que el agresor es conocido por la víctima, situación que constituye la mayoría de los casos de ASI (Servicio Médico Legal [SML], 2000).

En las ASI crónicas tienden a confluir las siguientes variables: agresor conocido por la víctima (que puede ser incestuoso), delito de violación que en algunos casos puede llegar a ser egosintónico, tiempo de acercamiento demorado, progresivo y no violento basado en la manipulación de la confianza, develación tardía e indirecta y una reacción a la develación negativa por parte de las figuras significativas (Castiglioni, Escaff \& Salinas, 2004; CAVAS, 2004; Huerta et al., 2002).

En Chile, una investigación estableció que la conjugación de un patrón tolerante ante la develación de las ASI y un número elevado de episodios abusivos, se asocian a un daño psicológico profundo y a alteraciones en las esferas estructurales de la personalidad, que implican alteración profunda de la psicosexualidad, alteración severa de la vinculación, inhibición social, relacional y/o afectiva extrema y disociación profunda; mientras que los niños que presentan un entorno con patrón intolerante y un número de eventos abusivos inferior a diez, manifiestan un daño leve-moderado (trastorno de estrés agudo, trastorno adaptativo y aquellos cuya sintomatología no permite configurar un cuadro) (Huerta et al., 2002).

Las secuelas de las ASI pueden cronificarse debido a una multiplicidad de factores, entre los que se encuentran la situación de abandono en que se encuentran las víctimas, la disfunción familiar (Poblete \& Varas, 1994) y la solidificación de estrategias de afrontamiento y creencias (Fulmer, 1992). De esta manera, los adultos que fueron victimizados sexualmente en su infancia pueden presentar los siguientes síntomas: trastorno limítrofe de personalidad, trastornos depresivos, conductas autodestructivas, trastornos de estrés postraumático, trastornos de ansiedad, trastornos disociativos, trastornos psicosomáticos, trastornos de conducta alimentaria, trastornos de la función sexual y algunos rasgos de personalidad inadecuados (Poblete \& Varas, 1994).

McLean y Gallop (2003) realizaron una investigación en EE.UU. que estableció que los diagnósticos conjuntos de estrés postraumático (TEPT) y trastorno limítrofe de personalidad (TLP) son significativamente más comunes en mujeres que reportaron haber sido abusadas tempranamente $(94.7 \%)$ en relación con aquéllas que reportaron haber sido victimizadas tardíamente $(0 \%)$. Estos autores hallaron también que las agresiones sexuales incestuosas y la cronicidad (más de 10 eventos) se asocian significativamente a la ocurrencia conjunta de ambos trastornos.

Dentro de las consecuencias psíquicas más graves producidas por las ASI se incluyen el desarrollo de trastorno antisocial de la personalidad (TAP) en la adultez (Luntz \& Widom, 1994) y TLP. Este último puede aparecer tanto en la niñez como en la adolescencia, presentando una alta asociación con las vivencias de abuso sexual, sobre todo si éste es crónico (Bleiberg, 1994; Bower, 1989; Harman, 2004; Heimann \& Habinger, 1993; Logfren, Bemporad, King, Lindem \& O'Driscoll, 1991; Meekings \& O’Brien, 2004). A este respecto, Meares, Stevenson y Gordon (1999, citado en Meekings \& O'Brien, 2004) estiman que un $60-80 \%$ de los pacientes con TLP fueron víctimas de ASI. Por otro lado, un 14\% de los sujetos que de niños padecieron ASI, maltrato físico y/o negligencia presentaron TAP en la adultez temprana, porcentaje que es estadísticamente significativo al compararse éste con el de la población general (Luntz \& Widom, 1994).

El diagnóstico de trastorno de personalidad en niños y adolescentes ha dado lugar a controversias en el ámbito científico, debido a que se ha sostenido que la personalidad no se ha conformado totalmente en estos sujetos. Sin embargo, puede argumentarse que algunos niños presentan un patrón inflexible y crónico de percibir, relacionarse y pensar, tanto respecto de sí mismos como de los otros, el cual es diferente del de otros niños de su misma etapa evolutiva que presentan una mayor flexibilidad y una identidad y personalidad apropiada para la edad (Kernberg, Weiner \& Bardenstein, 2002).

Debido a que la literatura especializada reporta una asociación más fuerte de las ASI con el TLP en comparación con los otros trastornos de personalidad, se procederá a continuación a revisar brevemente las principales características de este trastorno en la niñez, tanto en relación a su etiología, como a su sintomatología y comorbilidad.

Los niños con TLP presentan diversos síntomas. Los sintomas internalizantes se refieren a aquellos que el niño debe tramitar mentalmente. Esto son: dificultades en el manejo de la ansiedad, fobias, compulsiones, trastornos del sueño, trastornos somáticos, 
depresión, excesiva fluidez en el pensamiento y poca diferenciación entre fantasía y realidad. Los síntomas externalizantes, en cambio, son conductas abiertas tales como la dificultad en establecer relaciones con los otros y deficiencias en el control de impulsos, que incluyen dificultades en el manejo de la rabia y la postergación de gratificaciones, conductas parasuicidas, y fallas en la represión de materiales del proceso primario. Por último, los sintomas cognitivos, dependen de los dos tipos de síntomas descritos previamente y consisten en la falta de una autoimagen estable, fluctuación funcional entre lo neurótico y lo psicótico secundario a tranquilidad ambiental o amenaza, sentimientos crónicos de vacío y miedo al abandono (Bemporad et al., 1987 citado en Logfren et al., 1991; Bleiberg, 1994; King, Lindem \& O'Driscoll, 1991; Meekings \& O’Brien, 2004).

EL TLP en la infancia se acompaña comúnmente de trastornos en el Eje I, tales como trastorno de déficit atencional con hiperactividad, trastornos de aprendizaje, trastornos de conducta, trastornos ansiosos, trastornos del ánimo y trastornos alimentarios (Bleiberg, 1994; Harman, 2004).

La etiología del TLP en la infancia es compleja, debido a que numerosos factores inciden tanto en su génesis como en su desarrollo. A continuación se revisan brevemente estos factores:

1. Eventos traumáticos: se ha descrito que los niños con este trastorno provienen de familias caóticas y han experimentado estresores tales como abuso físico, sexual o emocional, negligencia o separaciones traumáticas (Bleiberg, 1994; Meekings \& O'Brien, 2004).

2. Psicopatología parental: los padres a menudo presentan psicopatología grave como depresión, abuso de sustancias y trastorno de personalidad antisocial (Bleiberg, 1994; Meekings \& O’Brien, 2004).

3. Interacciones tempranas: se ha observado madres que aunque durante la fase de separación-individuación son capaces de cuidar y acoger al bebé, desalientan tácita o abiertamente la búsqueda de independencia por parte de aquél (Bleiberg, 1994). Por otra parte, un apego ansioso-evitativo o una interrupción del apego contribuyen al desarrollo de este trastorno (Harman, 2004).

4. Aspectos neurológicos: la literatura ha reportado problemas de aprendizaje, trastorno de déficit atencional, anomalías en el electroencefalograma y disfunción en el lóbulo frontal (Harman, 2004; Meekings \& O'Brien, 2004).

5. Aspectos genéticos: se ha reportado que factores genéticos interactúan con factores psicosociales en la conformación de este trastorno (Meekings \& O’Brien, 2004).

Los trastornos de personalidad en la infancia tienden a perdurar hasta la adultez (Kernberg et al., 2002). Esto es válido sobre todo para el TLP, trastorno esquizoide de la personalidad y TAP (este último como continuación del trastorno disocial) (Kasen, Cohen, Skodol \& Johnson, 1999). Logfren et al. (1991) estudiaron a adultos que recibieron el diagnóstico de "patología limítrofe" durante su niñez (6-10 años de edad). Estos adultos no presentaron trastornos afectivos o esquizofrenia en el Eje I, pero el diagnóstico de patología limítrofe se mantuvo y el desempeño general era pobre (ya sea de tipo impulsivo-antisocial o de evitación esquizoide). Este hecho llevó a dichos autores a hipotetizar que el diagnóstico de patología limítrofe infantil parece ser un antecedente de un conjunto de trastornos de la personalidad en el adulto, existiendo por tanto una continuidad entre la psicopatología de la latencia con la de la adultez temprana.

En vista de que tanto el TLP como el TAP entrañan por un lado graves perturbaciones intrapsíquicas e interpersonales para el afectado que tienden a la persistencia y generalización, y que por otra parte ofrecen serias dificultades para el tratamiento (Harman, 2004; Kernberg et al., 2002; Luntz \& Widom, 1994), el diagnóstico de organización limítrofe de personalidad de los menores victimizados sexualmente tiene importancia tanto para la dimensión del daño psíquico resultante de estas transgresiones, como para el pronóstico de recuperabilidad y la orientación del tratamiento reparatorio (CAVAS, 2004).

Por último, no debe perderse nunca de vista el hecho de que la ocurrencia de TLP o trastorno disocial en un niño es sólo un indicio de ASI a corroborar, pues estos trastornos pueden haber sido ocasionados por factores ajenos a una situación sexualmente abusiva.

La hipótesis que guió la presente investigación fue que los niños y niñas víctimas de agresiones sexuales crónicas presentarían en mayor proporción una estructura u organización de personalidad limítrofe en la Prueba PBLL en relación con los niños y niñas de los que no se tuviera la sospecha de que hubieran sido agredidos sexualmente. Esta hipótesis se basa en el hecho de que las ASI crónicas afectarán la estructuración de personalidad de los menores afectados (CAVAS, 2004), redundando en el desarrollo de TLP, tanto en la niñez (Bleiberg, 1994; Bower, 1989, Harman, 2004; Heimann \& Habinger, 1993; Logfren et al., 1991; Meekings \& O’Brien, 2004), como posteriormente en la adolescencia y adultez (Fulmer, 1992; McLean \& Gallop, 2003; Poblete 
\& Varas, 1994). También el TAP en la adultez se ha asociado a ASI (Luntz et al., 1994). Cabe hacer notar que tanto el TLP como el TAP se enmarcan dentro de la organización limítrofe de la personalidad.

\section{Teoría de las Relaciones Objetales y Diagnóstico Estructural}

La teoría de las relaciones objetales desarrollada por Otto Kernberg $(1986,1987,1996,1997)$ se inscribe dentro de la psicología psicoanalítica del yo. Esta teoría enfatiza la importancia del desarrollo de las representaciones internalizadas de sí mismo y de los objetos en la configuración de la personalidad y las relaciones interpersonales.

Las relaciones objetales se internalizan mediante introyecciones, identificaciones y por la paulatina conformación de la identidad del yo. Estas relaciones objetales constan de imágenes o representaciones objetales, imágenes o representaciones del sí mismo y derivados o disposiciones instintivas a determinados estados afectivos (libidinales o agresivos) que ligan las representaciones anteriormente mencionadas. La ocurrencia de experiencias afectivas cumbre en la infancia son responsables en gran medida de la internalización de relaciones objetales primitivas escindidas. Por el contrario, los estados afectivos tranquilos posibilitan la creación de estructuras mnémicas de naturaleza cognitiva, discriminativa, que contribuyen al desarrollo del yo.

Kernberg $(1996,1997)$ propone un modelo de desarrollo de la personalidad en que ésta se va organizando en niveles cada vez más complejos e integrados. En este desarrollo el yo temprano debe llevar a cabo dos tareas fundamentales:

1. La diferenciación entre imágenes objetales y autoimágenes, que se logra gracias al desarrollo de las funciones de autonomía primaria. Esta tarea falla en las psicosis, donde existe una indiferenciación entre el sí mismo y el no-sí-mismo.

2. Integración de las imágenes objetales del sí mismo y las objetales de origen libidinal y agresivo. Esta tarea fracasa en los sujetos con organización limítrofe de la personalidad, debido principalmente al predominio de la agresión pregenital. De este modo se obstaculiza la integración del concepto de sí mismo, el establecimiento de relaciones objetales totales y el logro de la constancia objetal. El mecanismo defensivo de la escisión, separa las representaciones buenas del sí mismo y de los objetos como de los objetos buenos externos de las imágenes malas, para proteger a las primeras de las segundas. Se produce así la división del yo, lo que interfiere considerablemente en la integración del superyó. Este superyó primitivo es sádico con ideales fantásticos de poder, grandeza y perfección y no logra integrar las exigencias y metas sociales de manera realista.

Cuando las representaciones objetales internalizadas buenas y malas han sido integradas, se produce la integración del sí mismo y de los objetos, lo que posibilita una identidad del yo estable. Lo anterior permite la integración superyoica, que conlleva un manejo más flexible de los derivados instintivos por parte del yo. En este nivel superior de patología del carácter (neurótico), el superyó, aunque integrado sigue siendo duro y exigente y está centrado en la conflictiva de la sexualidad infantil. Existe constancia objetal, capacidad de mantener relaciones objetales estables y profundas y una identidad del yo estable. En la normalidad (que se inscribe dentro de la organización neurótica de personalidad) se presenta un superyó bien integrado, menos severo y punitivo que en las patologías del carácter neuróticas. Existe asimismo una integración de las tendencias pregenitales bajo el imperio de la genitalidad. La represión contra las representaciones objetales infantiles está complementada por un yo con funcionamiento flexible, de modo tal que se evidencia un establecimiento de relaciones armoniosas con el mundo externo.

Kernberg $(1986,1987,1996)$ propone una clasificación de la personalidad desde el punto de vista de las características estructurales intrapsíquicas y no desde un punto de vista descriptivo como la que plantea el DSM-IV (American Psychiatric Association, 2002). Este punto de vista estructural permite lograr una comprensión de la etiopatogenia y psicodinámica de los trastornos de personalidad. De esta manera, se ha podido establecer que a trastornos de personalidad descriptivamente diferentes subyace una configuración intrapsíquica similar, por ejemplo los trastornos limítrofe, esquizoide e histriónico de la personalidad se sitúan en la organización limítrofe de personalidad. Cabe destacar que Kernberg considera tanto la dimensión cuantitativa como cualitativa o categórica de los diferentes trastornos de personalidad.

Los criterios de clasificación que emplea este autor para el diagnóstico diferencial de las distintas organizaciones de personalidad son (Kernberg, 1986, 1987):

1. Identidad del Yo: se refiere a la presencia de un concepto integrado de la persona a través del tiem- 
po y en distintas situaciones. Involucra también un concepto integrado de los otros significativos.

2. Juicio de realidad: es la capacidad de diferenciarse a sí mismo de lo que no es uno mismo. Incluye el ser capaz de diferenciar el yo del no yo, distinguir el origen intrapsíquico del externo de los estímulos y mantener empatía con criterios sociales de realidad.

3. Mecanismos de defensa: los mecanismos defensivos altos, relacionados con la represión, se ven de forma indirecta y no afectan la relación psicoterapéutica en forma considerable; por el contrario, los mecanismos de defensa bajos o primitivos, relacionados con la escisión, aparecen y afectan inmediatamente la relación interpersonal, lo que facilita el diagnóstico.

A continuación, se esquematizan las principales características de las diferentes organizaciones o estructuras de personalidad (Kernberg, 1986, 1987):

1. Organización neurótica de personalidad: es la estructura normal. Se observa integridad del yo. El juicio de realidad está conservado. Los mecanismos de defensa son altos: represión, proyección, intelectualización, racionalización, negación avanzada y formaciones reactivas.

2. Organización limitrofe de personalidad: abarcan un grupo de trastornos de personalidad graves con características comunes en cuanto a estructura intrapsíquica, desarrollo, tratamiento y pronóstico. Existe una identidad del yo difusa, caracterizada por un concepto pobremente integrado de sí mismo y de los otros significativos que se evidencia en una experiencia de vacío crónico, autopercepciones contradictorias, conducta contradictoria que no puede integrarse emocionalmente y percepciones huecas, insípidas y empobrecidas de los demás. El juicio de realidad está mantenido, pero hay alteraciones en relación al sentido de realidad. Se utilizan defensas primitivas o bajas: escisión, identificación proyectiva, idealización primitiva, omnipotencia, control omnipotente, devaluación y negación primitiva. Un criterio adicional que permite el diagnóstico diferencial con la estructura neurótica es la presencia de manifestaciones no específicas de debilidad yoica: baja tolerancia a la ansiedad y déficit en el control de impulsos y capacidad de sublimación. Por otra parte, el grado y calidad de la integración del superyó permite diferenciar la organización limítrofe y psicótica de la neurótica, ya que en el último caso éste está bien integrado, aunque es muy severo. En cambio en la estructura limítrofe y psicótica existe un deterioro en la integración de esta instancia psíquica, caracterizado por precursores no integrados de la misma con representaciones primitivas (sádicas e idealizadas) de los objetos.

3. Organización psicótica de la personalidad: se incluyen los pacientes con psicosis clínicas y aquellos que aunque no cumplan con los criterios diagnósticos sí presentan esta estructura. No hay identidad yoica, excepto en psicóticos graves que tienen una personalidad psicótica. El juicio de realidad está perdido. Se aprecia la utilización de mecanismos defensivos primitivos: escisión, splitting, identificación proyectiva, idealización primitiva, omnipotencia, control omnipotente, devaluación y negación primitiva.

\section{La Prueba Persona Bajo la Lluvia en la Evalua- ción Clínico-Pericial de las Agresiones Sexuales Infantiles}

La Prueba Persona Bajo la Lluvia (PBLL) es una prueba proyectiva gráfica de cuya autoría no se tiene claridad, y que se utiliza en la práctica clínica como parte de una batería diagnóstica. Esta prueba evalúa la imagen corporal ante un evento estresante. El análisis de este test permite acceder a los conflictos intrapsíquicos, mecanismos de defensa y estructura de personalidad del evaluado. Puede aplicarse a niños y niñas de todas las edades, de manera individual o colectiva (Querol \& Cháves, 1997). Consiste en solicitar al evaluado que dibuje una persona bajo la lluvia en la forma que desee. Se le proporciona a este último una hoja, goma de borrar y lápices de colores.

La Prueba PBLL es utilizada como parte de una batería de pruebas psicológicas tendientes a constatar y dimensionar el daño psíquico asociado a ASI (Capella, Contreras, Guzmán, Miranda, Núñez et al., 2003; CAVAS, 2004; Servicio Nacional de Menores [SENAME], 2001, 2004). El extenso uso de esta prueba en la evaluación de ASI contrasta con las escasas investigaciones al respecto. Este último hecho hace que la validez y confiabilidad del instrumento sean limitadas.

Las investigadoras argentinas Barilari, Beigbeder y Colombo $(2000,2004)$ reportaron la existencia de 14 indicadores gráficos en la Prueba PBLL asociados a agresiones sexuales y maltrato infantil en el grupo de niños de 8 a 11 años de edad: dimensión pequeña, borrado, repaso, elementos fálicos, lluvia sectorizada, rayos, cabeza deteriorada, cinturón, ausencia de piso, ojos vacios, ausencia de manos, ausencia de detalles, figura incompleta o infantil, y ausencia de entorno. 
En Chile, Girardi y Pool (2006) encontraron que 7 indicadores gráficos en la Prueba PBLL, de un total de 45 indicadores que la literatura especializada vinculaba con ASI, se asociaban a este tipo de delitos en niños y niñas de 9 a 11 años de edad. Los 7 indicadores gráficos significativos $(p<$ .05) son: ausencia de piso, sonrisa maniaca, lluvia sectorizada, ausencia de paraguas, cabeza grande, ausencia de entorno y brazos cortos.

La investigación precedente (Girardi \& Pool, 2006) no consideró el significado psicológico de los indicadores gráficos hallados, por lo que en un trabajo posterior, Pool (2006), basándose en los datos de dicha investigación, sugirió que tales indicadores gráficos en su mayoría podrían estar relacionados a nivel de contenido con las dinámicas traumatogénicas descritas por Finkelhor y Browne (1985). De este modo, la dinámica traumatogénica de indefensión resultó ser la más frecuente, lo que se relaciona con el hecho de que los menores victimizados desarrollen miedo, ansiedad, sentimientos de impotencia y desesperación o una inusual necesidad de dominar. En menor medida aparecieron las dinámicas traumatogénicas de traición, que se asocia al dolor, depresión y desencantamiento del niño en relación al agresor y estigmatización, relacionada con los sentimientos de maldad, vergüenza y culpa del menor. La dinámica traumatogénica de sexualización traumática, asociada a preocupaciones sexuales, conductas sexuales repetitivas y connotaciones negativas relativas al sexo no se vinculó con ninguno de los indicadores gráficos (Pool, 2006).

La presente investigación puede considerarse un complemento de las investigaciones anteriormente mencionadas (Girardi \& Pool, 2006; Pool, 2006). El que se considere en este trabajo los dibujos de la Prueba PBLL como gestalten o totalidades en vez de tomar los indicadores por sí solos, aislados del gráfico total, proporciona una visión más holística del fenómeno del daño psíquico asociado a las ASI. Esto último permite inferir la personalidad total del menor evaluado, es decir, posibilita acceder a su diagnóstico estructural. Cabe hacer notar que esta inferencia es sólo aproximativa, ya que para la evaluación de la personalidad a través de pruebas proyectivas gráficas es necesaria la integración de los datos provenientes de distintas pruebas (batería diagnóstica) y de la observación del comportamiento del evaluado (Hammer, 1997c). Por otra parte, al basar la evaluación de la personalidad en el modelo teórico de las relaciones objetales de Kernberg
$(1986,1987,1996)$ se enriquece y profundiza la comprensión del fenómeno estudiado.

\section{Diagnóstico Estructural a Través de la Prueba Persona Bajo la Lluvia}

Las pruebas proyectivas gráficas se basan en la premisa de que el evaluado volcará en el dibujo su mundo interno a través del proceso psicológico de la proyección. Este tipo de pruebas da cuenta de los niveles predominantemente inconscientes de la personalidad y de aquellos contenidos que el evaluado no está dispuesto a revelar, de modo tal que estos test no son muy adecuados para predecir la conducta manifiesta (Hammer, 1997c). Levy (1997) refiere que los supuestos básicos subyacentes a la utilización de estas pruebas son:

1. Los dibujos están sobredeterminados, es decir obedecen a una variedad de determinantes, tanto internas como externas.

2. Los dibujos están determinados por factores psicodinámicos nucleares.

3. Estos factores psicodinámicos nucleares se relacionan con la imagen corporal.

4. Aunque diversos factores culturales, de entrenamiento, etc. determinen el gráfico, los factores caracterológicos pueden ser aislados, identificados y en parte cuantificados.

5. Las operaciones responsables del dibujo poseen una estructura gramática y sintáctica similar a las que gobiernan los símbolos oníricos, las estructuras de la fantasía y los desplazamientos somáticos.

Dentro de las ventajas que proporciona el uso de pruebas gráficas en el contexto clínico destacan su administración relativamente simple, tiempo de administración corto y que permite una apreciación rápida del evaluado, facilitación de la posterior aplicación de otros tests, capacidad de penetrar en capas profundas de la personalidad incluso con mayor profundidad que test proyectivos verbales como el CAT o el Rorschach y, por último, utilidad en el trabajo con niños que poseen una escasa educación, que son tímidos, deficientes mentales, etc. (Hammer, 1997a).

Las pruebas proyectivas gráficas en general han presentado problemas en relación a los procesos de validación científica que buscan la validez y confiabilidad de dichos instrumentos (Heidgerd, 1997; Masling, 1997; Thomas \& Jolley, 1998). Puede ser que esto se corresponda con la tendencia de muchas investigaciones a atomizar las producciones gráficas en componen- 
tes o indicadores y no considerar al gráfico como una totalidad (Hammer, 1997c; Heidgerd, 1997).

Una prueba proyectiva gráfica ampliamente utilizada en Chile es la Prueba PBLL, la cual da cuenta de la imagen corporal ante un evento estresante, la lluvia, lo que propicia la emergencia de defensas antes latentes en el individuo (Barilari, Beigbeder \& Colombo, 2004; Hammer, 1997b; Querol \& Cháves, 1997). Esta situación estresante ejerce gran presión sobre el yo del evaluado, por lo que se despliegan las defensas habituales de que hace uso esta instancia para mantener el equilibrio psíquico. Debido precisamente a que se provoca una gran ansiedad al yo, es que esta prueba resulta de gran utilidad para acceder a la estructura de personalidad. Por otra parte, el empleo de colores en la ejecución de la prueba, en contraposición a la tradicional utilización acromática del test, permite una mayor profundización en las capas de la personalidad, ya que se movilizan los afectos.

A partir de la experiencia clínica, Muñoz (2005) ha propuesto que los productos gráficos correspondientes a las distintas organizaciones de personalidad presentan características diferenciales, permitiendo por tanto efectuar un diagnóstico estructural.

A continuación se describen las características de los gráficos propias para cada estructura de personalidad (Muñoz, 2005):

1. Estructura Neurótica

- Gestalt conservada: lo graficado coincide con el objeto real.

- Delimitación lograda: las figuras presentan cierre, los objetos graficados están delimitados y separados entre sí.

- Cualidades centrales del objeto mantenidas: puede faltar alguna parte, pero es mínima y es la que se relaciona con el conflicto.

- Patología: se expresa en áreas reducidas, no en todo el gráfico. Puede haber sobreacentuaciones u omisiones, pero no se daña el gráfico significativamente. Pueden aparecer zonas confusas en un gráfico organizado.

- Movimiento: son dibujos que eventualmente expresan movimiento.

- Color: uso adecuado del color, es decir, existe coincidencia con el objeto real.

2. Estructura Limitrofe

- Gestalt: pueden o no encontrarse alteraciones, tales como objetos combinados en que se grafica por ejemplo un árbol-persona. Los objetos son reconocibles, tienen sus partes centrales conservadas, pero hay una parte mal integrada que no corresponde al objeto real (contaminación).

- Delimitaciones y Cierre: los objetos graficados presentan partes pegadas, lo que se vincula con lo simbiótico, no alcanzando a ser fusión, por ejemplo graficar un abrazo.

- Variabilidad entre los distintos objetos: en el mismo gráfico aparecen objetos bien logrados y otros no.

- Ataque a funciones adaptativas y ajuste a la realidad: existen alteraciones lógicas que se aprecian en la secuencia y perspectiva del dibujo, así como de los tamaños relacionales de los objetos. Se aprecian alteraciones a nivel de contenido, tales como ojos sin pupila, ausencia de manos, pies, etc.

- Figura Humana: figuras relativamente completas a las que le faltan partes. Pueden representar también figuras humanoides (superhéroe, ángel, Jesucristo, figuras combinadas o desvitalizadas, etc.). Aparece algo vacío en la figura como por ejemplo los ojos.

- Color: el uso de color varía según el tipo de personalidad limítrofe; en los esquizoides no aparece color, en la personalidad infantil se aprecia mucho color que está mal integrado (manchones), en las personalidades psicopáticas, el color no coincide con el objeto real.

3. Estructura Psicótica

- Gestalt: no está conservada. No hay correlato con la realidad. Cada objeto muestra desorganización. Los dibujos son extraños, bizarros. Aparecen pedazos de objetos, ya que se evacuan en la hoja contenidos psíquicos.

- Sintesis: los objetos no tienen síntesis ni cierre.

- Movimiento: no hay movimiento armónico. Existe rigidez como de estatua en las figuras. Las figuras humanas son desvitalizadas y cuando se logra producir detalles se producen transparencias.

- Ataque masivo a funciones adaptativas y de ajuste a la realidad: eliminan, rayan, etc. los órganos perceptivos.

- Alteraciones lógicas: a nivel de tamaño relacional entre objetos, perspectiva y volumen.

- Color: existe variabilidad, dependiendo del grado de deterioro y tipo de psicopatología.

Las Figuras 1 y 2 ejemplifican las producciones gráficas neurótica y limítrofe respectivamente. Estos dibujos corresponden ambos a niños del grupo de control. 


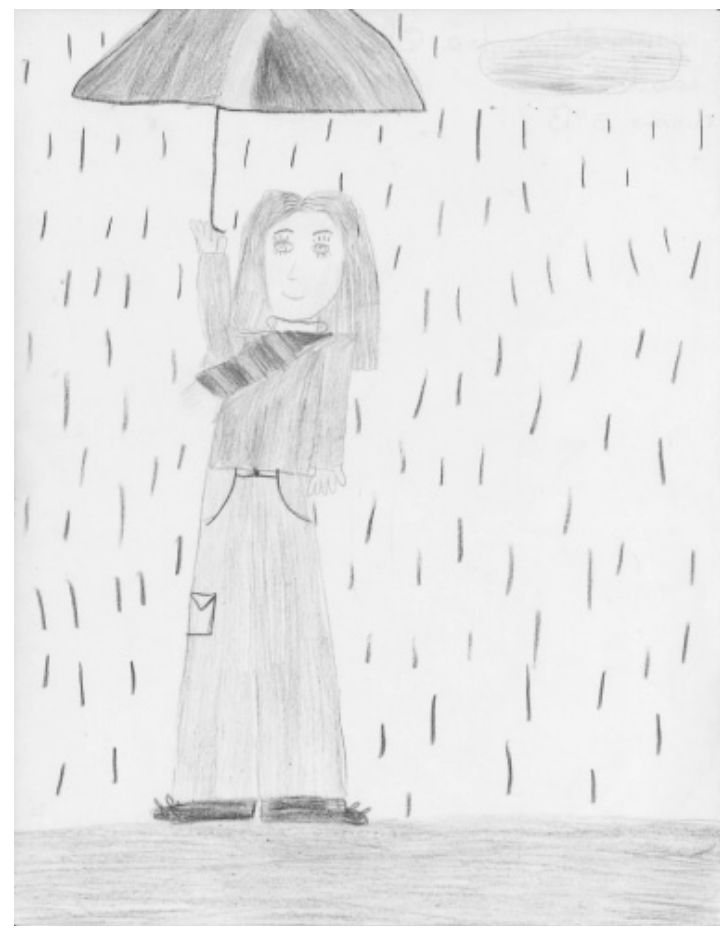

Figura 1. Dibujo de PBLL neurótico de niña de 10 años (grupo de control).

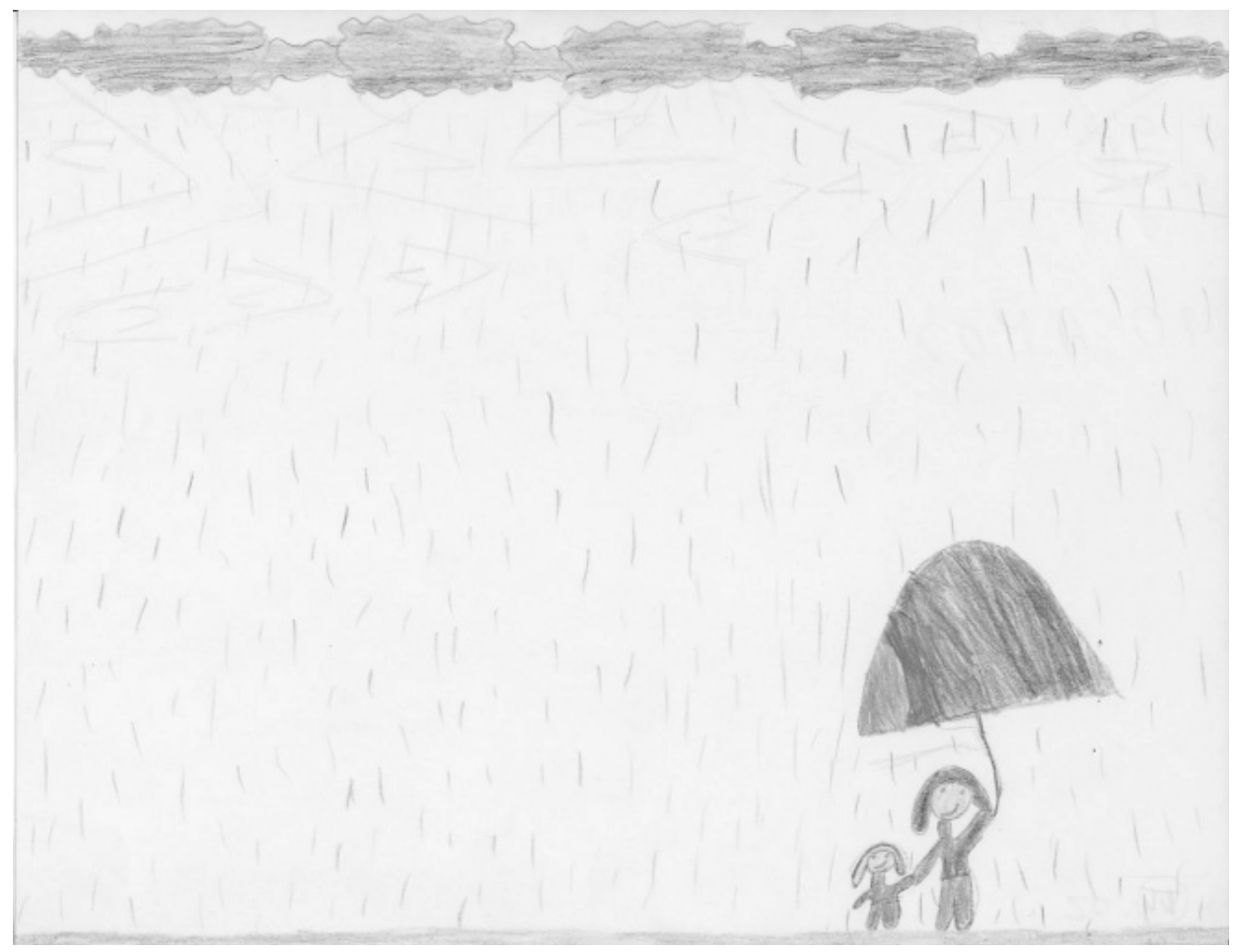

Figura 2. Dibujo de PBLL limítrofe de niña de 10 años (grupo de control). 


\section{Método}

Esta investigación tuvo como objetivo establecer el diagnóstico estructural a través de la Prueba PBLL en niños/as de 9 a 11 años de edad, víctimas de agresiones sexuales crónicas.

\section{Diseño}

Estudio transversal correlacional. Diseño no experimental. Se evaluaron los gráficos PBLL según los criterios estipulados previamente (Muñoz, 2005), para establecer el diagnóstico estructural de personalidad (neurótica, limítrofe o psicótica) en menores de 9 a 11 años de edad víctimas de agresiones sexuales crónicas.

\section{Participantes}

El conglomerado del que se extrae la muestra lo conforman niños y niñas de la Región Metropolitana entre 9 y 11 años de edad, de nivel socio-económico bajo y víctimas de agresiones sexuales crónicas. Estos niños deben haber realizado la prueba PBLL en una fase inicial de la atención psicológica en un centro especializado.

El grupo de estudio lo constituyen niños y niñas entre 9 y 11 años de edad víctimas de agresiones sexuales crónicas, atendidas en el CAVAS Metropolitano y en el Centro de Intervención Especializado en Maltrato Grave [CIE] de Peñalolén. Se consideraron los casos que incluyeran los delitos de abuso sexual y/o violación. El criterio de cronicidad está dado por el número de transgresiones (10 episodios o más). La información respecto a la cronicidad de las ASI fue recabada por los profesionales de dichos centros y constaba en la ficha clínica de cada niño. El nivel socio-económico de los sujetos del grupo de estudio se determinó por los antecedentes de la evaluación social realizada por cada una de las instituciones. Dicha información constaba en la ficha clínica de cada niño.

El grupo de control fue extraído de un colegio municipalizado de la comuna de La Pintana, comuna representativa del nivel socio-económico bajo (Rodríguez \& Winchester, 2001). Este grupo se conformó con niños/as de los que, tanto el profesor jefe como el director del establecimiento, no tuvieran la sospecha de que hubieran sido agredidos sexualmente.

Tanto el grupo de estudio como el grupo de control quedaron constituidos por 25 niños y niñas entre 9 y 11 años de edad. Se configuraron de esta manera grupos con las mismas características en relación al nivel socio-económico y a la dispersión por edad y por sexo (ver Figura 3).

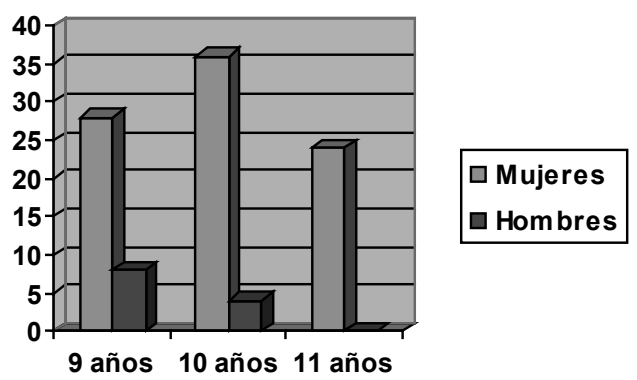

Figura 3. Distribución en porcentajes de acuerdo a edad y sexo del grupo de estudio.
Para intentar controlar la influencia de ciertas variables -especificadas en la literatura- que pudiesen interferir con los resultados, se impusieron las siguientes restricciones a la muestra:

1. Los dibujos del grupo de niños y niñas víctimas de agresiones sexuales solicitados a los distintos centros de atención debieron haberse elaborado en una fase inicial de la atención clínica. Se determinó un tiempo máximo de 3 meses, considerando los modelos de intervención de algunos centros nacionales (CAVAS, 2004; SENAME, 2004).

2. Los niños y niñas de ambos grupos no debían presentar un diagnóstico de retraso mental.

\section{Procedimiento}

La aplicación de la Prueba PBLL en el grupo de niños víctimas de ASI fue llevada a cabo por distintos psicólogos pertenecientes a los centros especializados ya mencionados. Dicha prueba se realizó durante el proceso psicodiagnóstico y fue de aplicación individual.

La aplicación de la Prueba PBLL en el grupo de control fue llevada a cabo por el autor y se realizó colectivamente por limitaciones de acceso a la muestra. Los participantes fueron dispuestos alrededor de mesas. Tenían a su disposición lápices de colores y goma de borrar. Los participantes recibieron las instrucciones en voz alta. No se reforzaron las conductas asociadas a la producción gráfica, pero sí se atendió a las dudas que surgiesen de manera individual.

Tanto los dibujos del grupo de estudio como de control fueron analizados por el investigador. No fue posible utilizar ningún procedimiento de ciego debido a las restricciones que impone el carácter especial de las producciones gráficas del grupo de estudio, pues éstas constituyen material probatorio judicial.

\section{Instrumento}

La prueba PBLL es una prueba proyectiva gráfica que permite acceder a contenidos inconscientes del evaluado, posibilitando realizar el diagnóstico estructural de personalidad.

\section{Análisis de datos}

En el análisis de los datos se utilizó las tablas de contingencia de Chi cuadrado $(\chi 2)$.

\section{Resultados}

Los resultados arrojados por esta investigación sugieren que la organización limítrofe de personalidad, evaluada mediante la Prueba PBLL, se asocia en forma altamente significativa $(p=0.005 ; \chi 2=8, g l 1)$ con la variable ex post facto. De esta manera, el grupo de estudio presenta significativamente una mayor proporción de niños/as con una estructura de personalidad limítrofe en comparación con el grupo de control.

A nivel descriptivo, se encontró en el grupo de estudio un $28 \%$ de organización de personalidad neurótica, un $72 \%$ de organización limítrofe y un $0 \%$ de organización psicótica. Por otra parte, los porcentajes hallados en el grupo de control para cada organización de personalidad fueron: $72 \%$ organi- 
zación neurótica, $28 \%$ organización limítrofe y $0 \%$ organización psicótica. En la Figura 4 se muestran gráficamente tales porcentajes.

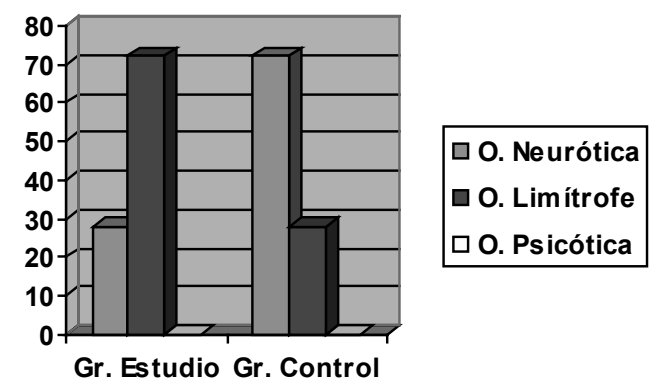

Figura 4. Porcentajes de cada tipo de estructura de personalidad para grupo de estudio y de control.

\section{Discusión}

Los resultados arrojados por esta investigación sugieren que los niños y niñas víctimas de agresiones sexuales crónicas presentan significativamente una mayor proporción de estructura de personalidad limítrofe, en relación a los niños y niñas de los que no se tenía la sospecha de que hubiesen sido victimizados. Por tanto, la hipótesis que guió este trabajo se vio confirmada. De esta manera es posible sostener que los menores crónicamente vulnerados en sus derechos sexuales presentan graves perturbaciones en relación a la estructuración de su personalidad, lo que conlleva profundas secuelas a nivel psíquico, interpersonal y afectivo. Estas consecuencias tenderán a la cristalización o intensificación en el futuro. Por lo anterior, el pronóstico de recuperabilidad de estos niños es más bien reservado.

El hecho de que un porcentaje no menor de niños del grupo de control posea una estructura de personalidad limítrofe debe entenderse sobre todo teniendo en cuenta el contexto de deprivación socio-cultural y de disfunción familiar de algunos de estos menores, lo que probablemente favorece las dificultades vinculares tempranas y diversos procesos de victimización no sexuales. Otro factor que puede estar incidiendo en el fenómeno anteriormente descrito, aunque con un peso probablemente bastante inferior, radica en la posible presencia de una cifra negra de casos de ASI no develados en el grupo de estudio.

A nivel de la psicodinámica implicada en la estructura de personalidad limítrofe, se hipotetiza que los menores crónicamente vulnerados en sus derechos sexuales presentan una fijación o regresión responsable de un funcionamiento predominantemente preedípico. Los eventos sexualmente abusivos pueden constituirse en una experiencia afectiva cumbre que recuerde un nivel de funcionamiento previo ya superado, el cual entraña una relación objetal específica en donde la representación del sí mismo es vista como amenazada o incluso destruida por un objeto sádico persecutorio, ambas imágenes se unen bajo la primacía de un estado afectivo agresivo. La disociación defensiva de las imágenes objetales y del sí mismo no permite el acceso a la constancia objetal. La persistencia en la utilización de mecanismos primitivos va debilitando progresivamente al yo, y por tanto el sentido del sí mismo se torna difuso. De esta manera, tanto los objetos como el sí mismo aparecen simultánea o alternativamente como objetos parciales buenos idealizados y malos devaluados. Por otra parte, la predominancia de los precursores sádicos del superyó contribuye a una orientación paranoide de las relaciones objetales. Lo anterior junto con la tendencia a la identificación proyectiva de contenidos agresivos en los objetos, conlleva a un ajuste caótico a la realidad social.

Cabe destacar que el hecho de que las ASI crónicas se asocien -en la Prueba PBLL- tan estrechamente con la estructura de personalidad limítrofe, se constituye en un fuerte argumento en favor del uso de esta prueba en contextos clínico-periciales, lo que contrasta con los resultados reportados por Girardi y Pool (2005). Estos autores encontraron una baja presencia de los indicadores gráficos asociados a ASI por la literatura especializada tanto en el grupo de estudio como en el de control, por lo que sostienen que la Prueba PBLL logra discriminar en forma limitada entre las representaciones gráficas de niños/as víctimas de agresiones sexuales y las de niños/as que no han sido vulnerados en sus derechos sexuales. Esto puede ser el resultado de que en tal investigación se realizó un análisis basado solamente en la presencia o ausencia de indicadores gráficos y no se consideró la producción gráfica como una Gestalt.

No debe perderse nunca de vista el hecho de que no es posible establecer una relación directa entre organización limítrofe de personalidad y ASI crónicas, ya que estas últimas producen daño psíquico que no siempre modifica la estructura de personalidad. Por otra parte, la configuración de la personalidad es un proceso que depende de múltiples factores. En este sentido la Prueba PBLL 
confiere solamente indicios que permiten sospechar de la ocurrencia de ASI. Debe recordarse, en todo caso, que este instrumento proyectivo debe emplearse conjuntamente con otras herramientas psicodiagnósticas.

El hecho de que no se encontrasen producciones gráficas psicóticas en el grupo de estudio ni en el de control da cuenta del bajo porcentaje en que esta organización de personalidad se encuentra en la población infantil. Por otra parte, puede sostenerse que las ASI no se constituyen en un factor que incida en el desarrollo de una estructura psicótica, lo cual concuerda con la inexistencia de referencias a este respecto en la literatura especializada.

En relación al tratamiento psicoterapéutico de las ASI crónicas debe tenerse presente la severidad del daño psíquico y la alta asociación con organización limítrofe de la personalidad que este tipo de transgresiones entraña. Las secuelas psíquicas probablemente no remitirán sin un tratamiento psicoterapéutico especializado de considerable complejidad y relativamente larga duración. A este respecto, quizás sea necesaria la implementación de intervenciones en distintos momentos del ciclo vital del sujeto, a medida que éste sea cada vez más capaz de simbolizar su experiencia (Perrone $\&$ Bak, 1995). A partir de los resultados, se hace patente la necesidad de adoptar en el tratamiento de menores abusados crónicamente, los programas e intervenciones psicoterapéuticas que tiendan a la modificación de la estructura de personalidad y no meramente al alivio sintomatológico, por lo que tanto las intervenciones terapéuticas como el criterio para el alta deben contemplar junto con los criterios conductual, cognitivo y afectivo, los conflictos psicodinámicos subyacentes.

En relación a las limitaciones de la presente investigación, debe tenerse en cuenta la escasa investigación nacional y extranjera que existe sobre la Prueba PBLL en la evaluación de ASI, por lo que se hace necesaria la realización de futuras investigaciones para incrementar la validez y confiabilidad del instrumento. Otro aspecto que limita los resultados es la distinta modalidad de aplicación del test (individual $\mathrm{v} / \mathrm{s}$ colectivo).

Algunas líneas de investigación que pueden desarrollarse a futuro son la evaluación del diagnóstico estructural en relación a otros rangos etáreos y niveles socio-económicos. Con respecto a la variable edad, debe recordarse que los dibujos de los niños/as varían evolutivamente (Barilari, Beigbeder \& Colombo, 2004; Koppitz, 2002).
Constituyen también posibles líneas de investigación la evaluación diferencial de las variables mediadoras del impacto de las agresiones sexuales infantiles. Así, se podría realizar un diagnóstico estructural en niños y niñas víctimas de abuso sexual incestuoso, intra y/o extrafamiliar, ya que cada tipo de agresión sexual entraña una fenomenología particular. Por otra parte, se necesitan investigaciones que incorporen las verbalizaciones espontáneas y el relato que efectúa el niño en relación a su producción gráfica. Finalmente, se pueden comparar los resultados de la presente investigación con los de otros trabajos que establezcan el diagnóstico estructural en niños y niñas víctimas de ASI a través de otras pruebas proyectivas gráficas, como por ejemplo H-T-P, Dibujo de la Figura Humana, o Dibujo de la Familia.

\section{Referencias}

American Psychiatric Association. (2002). Manual diagnóstico y estadistico de los trastornos mentales DSM-IV-TR. Barcelona: Masson.

Barilari, Z., Beigbeder, C. \& Colombo, R. (2000). Indicadores de abuso y maltrato infantil en la prueba gráfica "Persona bajo la lluvia”. Buenos Aires: Paidós.

Barilari, Z., Beigbeder, C. \& Colombo, R. (2004). Abuso y maltrato infantil. Indicadores en "Persona bajo la lluvia". Buenos Aires: Cauquén.

Bleiberg, E. (1994). Borderline disorders in children and adolescents: The concept, the diagnosis, and the controversies [Versión electrónica]. Bulletin of the Menninger Clinic, 58(2), 169-196.

Bower, B. (1989). Crossing the "borderline" of child abuse. Science News, 135(16), 246.

Capella, C., Contreras, L., Guzmán, L., Miranda, J., Núñez, L. \& Vergara, P. (2003). Una aproximación clínica a las producciones gráficas de niños(as) víctimas de agresión sexual. En Asociación Iberoamericana de Psicología Jurídica (Ed.), Anales V Congreso Iberoamericano de Psicología Jurídica (pp. 267-278). Santiago, Chile.

Castiglioni, P., Escaff, E. \& Salinas, M. (2004). Agresiones sexuales: Una aproximación comprensiva para un diseño de intervención y evaluación pericial. Manuscrito no publicado, Universidad de Chile, Santiago.

Centro de Asistencia a Víctimas de Atentados Sexuales. (2004). CAVAS Metropolitano: 16 años de experiencia. Santiago: Autor.

Finkelhor, D. \& Browne, A. (1985). The traumatic impact of child abuse: A conceptualization. American Journal of Orthopsychiatry, 55(4), 530-541.

Fulmer, J. F. (1992). La presentación oculta de los adultos supervivientes de incesto u otras agresiones sexuales en la infancia. En S. Stiht, M. Williams \& K. Rosen (Eds.), Psicosociología de la violencia en el hogar. Estudios, consecuencias y tratamiento (pp. 257-285). Barcelona: Descleé de Brouwer.

Girardi, K. \& Pool, A. (2006). Indicadores gráficos asociados a agresiones sexuales infantiles en la Prueba Persona Bajo la Lluvia. Un estudio descriptivo-comparativo. Cuadernos de Psicología Jurídica, 3, 41-57. 
Hammer, E. F. (1997a). Áreas que resultan especialmente ventajosas para los dibujos proyectivos. En E. F. Hammer (Ed.), Test proyectivos gráficos (pp. 365-371). Buenos Aires: Paidós.

Hammer, E. F. (1997b). Diversas técnicas proyectivas gráficas. En E. F. Hammer (Ed.), Tests proyectivos gráficos (pp. 235-268). Buenos Aires: Paidós.

Hammer, E. F. (1997c). Retrospectiva y prospectiva. En E. F. Hammer (Ed.), Tests proyectivos gráficos (pp. 387-393). Buenos Aires: Paidós.

Harman, M. J. (2004). Children at-risk for borderline personality disorder. Journal of Contemporary Psychotherapy, 34(3), 279-290.

Heidgerd, E. (1997). La investigación en las técnicas gráficas. En E. F. Hammer (Ed.), Tests proyectivos gráficos (pp. 297-309). Buenos Aires: Paidós.

Heimann, J. P. \& Habinger, E. (1993). Revisión del trastorno de personalidad borderline en la infancia y adolescencia. Revista Chilena de Neuropsiquiatría, 31, 25-35.

Huerta, S., Maric, V. \& Navarro, C. (2002). Factores que intervienen en el impacto del abuso incestuoso sobre la víctima. Terapia Psicológica, 38(2), 117-124.

Intebi, I. (1998). Abuso sexual infantil. En las mejores familias. Barcelona: Gránica.

Johnson, C. F. (2004). Child sexual abuse [Versión electrónica]. The Lancet, 364, 462-470.

Kasen, S., Cohen, P., Skodol, A. E., Johnson, J. G. \& Brook, J. S. (1999). Influence of child and adolescent psychiatric disorders on young adult personality disorder. The American Journal of Psychiatry, 156(10), 1529-1535.

Kernberg, O. F. (1986). Trastornos de la personalidad. Revista de Psiquiatría, III, 155-157.

Kernberg, O. F. (1987). Trastornos graves de la personalidad. Estrategias psicoterapéuticas. México: El Manual Moderno.

Kernberg, O. F. (1996). La teoría de las relaciones objetales y el psicoanálisis clínico. México: Paidós.

Kernberg, O. F. (1997). La agresión en las perversiones y en los desórdenes de la personalidad. Buenos Aires: Paidós.

Kernberg, P. F., Weiner, A. S. \& Bardenstein, K. K. (2002). Trastornos de la personalidad en niños y adolescentes. México: El Manual Moderno.

Koppitz, E. (2002). El dibujo de la figura humana en los niños. Buenos Aires: Guadalupe.

Levy, S. (1997). Dibujo proyectivo de la figura humana. En E. F. Hammer (Ed.), Tests proyectivos gráficos (pp. 65-82). Buenos Aires: Paidós.

Lofgren, D. P., Bemporad, J., King, J., Lindem, K. \& O’Driscoll, M. A. (1991). A prospective follow-up study of so-called borderline children. The American Journal of Psychiatry, 148(11), 1541-1547.

Luntz, B. K. \& Widom, C. S. (1994). Antisocial personality disorder in abused and neglected children grown up. The American Journal of Psychiatry, 151(5), 670-674.
Masling, J. M. (1997). On the nature and utility of projective test and objective test. Journal of Personality Assessment, 69(2), 257-270.

McLean, L. M. \& Gallop, R. (2003). Implications of childhood sexual abuse for adult borderline personality disorder and complex posttraumatic stress disorder. The American Journal of Psychiatry, 160(2), 369-371.

Meekings, C. \& O'Brien, L. (2004). Borderline pathology in children and adolescents. International Journal of Mental Health Nursing, 13, 152-163.

Miotto, N. (2001). Abuso sexual de menores. Complejidad diagnóstica. En Asociación Iberoamericana de Psicología Jurídica (Ed.), Anales IV Congreso Iberoamericano de Psicología Jurídica (pp. 31-57). Madrid, España.

Molnar, B. E., Buka, S. L. \& Kessler, R. C. (2001). Child sexual abuse and subsequent psychopathology: Results from the National Comorbidity Survey. American Journal of Public Health, 91(5), 753-760.

Muñoz, X. (2005). Las pruebas proyectivas gráficas en el psicodiagnóstico y en la psicoterapia. Manuscrito no publicado, Universidad de Chile, Santiago.

Perrone, R. \& Bak, F. (1999). Secuelas del abuso sexual en el desarrollo del pensamiento. Terapia Psicológica, 7(3), 131-136.

Poblete, A. \& Varas, Y. (1994). Abuso sexual en la infancia y psicopatología en la mujer. En Anales del Primer Congreso Nacional de Mujer y Salud Mental (pp. 204-208). Santiago, Chile.

Pool, A. (2006). Análisis desde el modelo traumatogénico de los indicadores gráficos asociados a agresiones sexuales infantiles en la Prueba Persona Bajo la Lluvia. Psykhe, 15(1), 45-55.

Querol, S. \& Cháves M. (1997). Adaptación y aplicación del Test de la Persona Bajo la Lluvia. Buenos Aires: JVE Psiqué.

Rodríguez, A. \& Winchester, L. (2001). Santiago de Chile: Metropolización, globalización, desigualdad. Eure, 27(80), 121-139.

Servicio Médico Legal. (2001). Anuario Estadístico Servicio Médico Legal 2000. Recuperado el 22 de Noviembre de 2004, desde: http://www.sml.cl/pdf/Anuario\%202000.pdf

Servicio Nacional de Menores. (2001). Técnicas de diagnóstico $y$ psicoterapia para reparación en niños y adolescentes víctimas de abuso sexual. Documento de trabajo $N^{\circ} 17$. Santiago: Autor.

Servicio Nacional de Menores. (2004). Estudio peritajes sicológicos en abuso sexual infantil. Recuperado el 22 de Noviembre de 2004, desde: http://www.sename.cl./interior/publicaciones/estudios5.pdf

Thomas, G. V. \& Jolley, R. P. (1998). Drawing conclusions: A re-examination of empirical and conceptual bases for psychological evaluation of children from their drawings. The British Journal of Clinical Psychology, 37(2), 127-139. 